\title{
Aplicação do sistema de gestão da qualidade BPF (boas práticas de fabricação) na indústria de produtos farmacêuticos veterinários
}

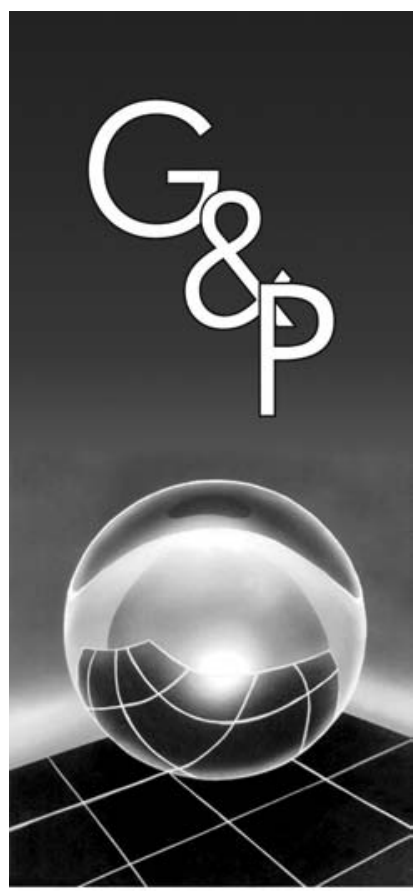

\author{
Felipe Araújo Calarge \\ Eduardo Guilherme Satolo \\ Luiz Fernando Satolo
}

Resumo

A necessidade de desenvolvimento de métodos de controle e gestão da qualidade tem se colocado como um fator de melhoria da competitividade e permanência das empresas em seus setores de atuação. No entanto, em alguns segmentos industriais, o controle e a gestão da qualidade se dão considerando também exigências de atendimento a normas e legislações governamentais, como é o caso do segmento de empresas fabricantes de produtos veterinários no Brasil. Este artigo descreve os principais aspectos e resultados de uma pesquisa tipo survey realizada com o objetivo de analisar se as empresas fabricantes de produtos veterinários estão se estruturando para aplicarem as boas práticas de fabricação, como um sistema de controle e gestão da qualidade. Por meio da condução de um levantamento bibliográfico, foram descritos aspectos relativos ao contexto de competitividade do agronegócio e do mercado de produtos veterinários, bem como dos principais tópicos relativos às bases normativas com ênfase nas boas práticas de fabricação. A execução da pesquisa se deu por meio da condução de uma survey em empresas do segmento farmacêutico veterinário, buscando-se caracterizar o método de pesquisa adotado, bem como relatos e dados obtidos. O trabalho conclui que as empresas fabricantes de produtos veterinários estão implantando as Boas Práticas de Fabricação, e demonstra, entre outros aspectos, que isto está motivado por uma gestão eficaz de seus recursos produtivos ao invés de um mero atendimento da legislação governamental.

Palavras-chave: Boas práticas de fabricação. BPF. Indústria farmacêutica veterinária. Gestão da qualidade.

\section{Introdução}

O segmento do agronegócio tem apresentado um vertiginoso crescimento econômico na última década no Brasil, sendo responsável atualmente por aproximadamente $27 \%$ do produto interno bruto e $37 \%$ da mão-de-obra empregada no país, caracterizando-se principalmente pela utilização de tecnologias inovadoras, modernas técnicas de melhoramento da qualidade do produto, e gestão eficaz do negócio (BRASIL, 2004b).

Aliada a esta situação, a exportação de produtos agropecuários tem exigido um esforço significativo no sentido de se adequar a normas e procedimentos legais relativos à garantia e ao controle da qualidade de produtos e/ou processos produtivos. Da mesma maneira, setores tradicionais da pecuária nacional, ou seja, criadores de bovinos, suínos e ovinos, têm procurado se adequar às

exigências de mercados externos e melhorar a produtividade de seus plantéis.

Dentro desta conjuntura de crescimento, qualificação e inovação do segmento do agronegócio no Brasil, as empresas atuantes nestes mercados também têm se desdobrado no sentido de aumentarem sua competitividade, fundamentalmente por meio de melhoria na qualidade (produtos/processos) e diminuição de custos, passando assim por processos de reestruturação e reorganização, que em muitos casos têm se dado em escala de mercados globais.

Particularmente, no que se refere ao mercado de produtos e medicamentos veterinários, a situação é semelhante, ou seja, empresas da indústria agroquímica têm investido em novas tecnologias para o desenvolvimento de produtos que minorem os impactos ambientais, 
bem como proporcionem eficácia e lucratividade na sua utilização. Se esta situação competitiva é árdua e dispendiosa para grandes empresas multinacionais, podem-se imaginar as dificuldades que se colocam para as pequenas e médias empresas do segmento de produtos e medicamentos veterinários, as quais muitas vezes são compelidas a atuarem em mercados marginais por não disporem de recursos humanos e financeiros para inovação de produtos e melhoria nas práticas de gestão organizacional e de processos produtivos.

Outro fator que retrata as dificuldades enfrentadas pelas empresas fabricantes de produtos farmacêuticos veterinários, refere-se às obrigações legais relativas ao controle e à avaliação das condições de fabricação e garantia da qualidade dos produtos fabricados. Um exemplo deste tipo de controle e avaliação dos produtos industrializados se dá por meio da Regulamentação de boas práticas de fabricação (BPFs) de produtos de uso veterinário, estabelecida pelo Ministério da Agricultura, Pecuária e Abastecimento (MAPA, 2006) no ano de 2003. É neste contexto que se trata a discussão e a proposta deste artigo, o qual tem por objetivo geral a verificação da utilização das BPFs em empresas fabricantes de produtos farmacêuticos veterinários.

As BPFs (boas práticas de fabricação) ou GMP (good manufacturing practices) são "um conjunto de normas obrigatórias que estabeleceme padronizam procedimentos e conceitos de boa qualidade para produtos, processos e serviços, visando atender aos padrões mínimos estabelecidos por órgãos reguladores governamentais nacionais e internacionais, cuja incumbência é zelar pelo bemestar da comunidade" (PEREIRA FILHO; BARROCO, 2004).

Desta maneira, este artigo busca por meio de uma revisão da literatura, contextualizar aspectos da relevância do agronegócio e do segmento de produtos veterinários no Brasil, bem como descrever de maneira cronológica o surgimento e a estruturação das BPFs como um sistema de controle e gestão da qualidade neste segmento industrial. Em seguida, é feita uma descrição da metodologia de pesquisa adotada na condução deste estudo, bem como seus principais fatores delineadores. $\mathrm{Na}$ análise de resultados consta uma descrição do porte econômico das empresas pesquisadas, em termos de seu faturamento anual. Os principais resultados da pesquisa são analisados considerando os fatores motivadores para a implementação das BPFs, bem como os aspectos dificultadores e os benefícios advindos desta implementação em relação a práticas de melhorias da qualidade e produtividade nestas empresas. É apresentada também uma seção que realiza a análise da correlação entre os diversos tópicos pesquisados em função do porte das empresas respondentes. Por fim, apresenta-se uma descrição das principais conclusões e recomendações oriundas da pesquisa.

\section{Relevância do agronegócio e panorama do segmento de produtos veterinários no Brasil}

O agronegócio brasileiro tem sido reconhecido nesta última década como uma importante fonte geradora de receitas de exportação, viabilizando também a importação de bens e serviços requeridos pela economia nacional. Graças a um volume de produção crescente e custos de produção decrescentes, resultado do uso de técnicas e tecnologias eficientes e acessíveis aos produtores, estimativas indicam que entre 1990 e 2003 o agronegócio brasileiro registrou um crescimento médio de $1,9 \%$ ao ano (WORLD BANK, 2005).

Estes resultados são também constatados ao se verificar que a partir de 1994 o segmento do agronegócio vem contribuindo decisivamente para resultados positivos observados na economia nacional, observando-se que no ano de 2005 este segmento foi responsável por 34\% do produto interno bruto (PIB), gerando $37 \%$ do total de empregos disponíveis, garantindo assim $85 \%$ do superávit na balança comercial, ou seja, US\$ 38,417 bilhões, com destaque para a exportação de carnes, de produtos do complexo da soja e da agroindústria canavieira, que representaram cerca de $52 \%$ do total das exportações brasileiras (MINISTÉRIO DA AGRICULTURA, PECUÁRIA E ABASTECIMENTO, 2006).

Estes resultados expressivos explicam-se em parte pelos seguintes fatores principais (FIESP \& CIESP, 2004):

a) mudança no padrão de financiamento ao setor agrícola pelo poder público a partir da década de 90 , em que a política agrícola oficial passou a privilegiar programas nos quais os riscos ficavam com os produtores;

b) intensa competitividade do mercado externo, fazendo com que o setor do agronegócio atingisse níveis maiores de eficiência econômica para conseguir competir nestes mercados; e

c) apoio governamental e de empresas privadas à pesquisa e desenvolvimento na área agrícola e de pecuária, conduzidas em centros de pesquisa e transferência tecnológica, citando como um dos exemplos a Embrapa (Empresa Brasileira de Pesquisa Agropecuária).

Dessa forma, aspectos relacionados à melhoria da gestão dos recursos produtivos, bem como uma melhor capacitação gerencial têm sido um fator importante de competitividade na cadeia de produção do segmento do agronegócio (MAKIYA; ROTONDARO, 2002; SCALCO; TOLEDO, 2002; CGEE; 2006).

No que diz respeito especificamente ao setor de agropecuária, verifica-se que de 1990 a 2003 a produção de carne bovina aumentou $85,2 \%$ (uma média de $6,1 \%$ ao 
ano), passando de 4,1 milhões para 7,6 milhões de toneladas produzidas. Nesse período, a suinocultura cresceu 173,3\% (média de 12,4\% ao ano), saltando de 1 milhão para 2,87 milhões de toneladas produzidas. O complexo de carnes, que inclui outros tipos do produto, também tem investido em pesquisa e desenvolvimento, por intermédio do melhoramento genético e na certificação de origem do produto (TORTUGA COMPANHIA ZOOTÉCNICA AGRÁRIA, 2005; PORTAL DO AGRONEGÓCIO, 2006).

Outro aspecto importante é o oferecimento de novos produtos demandados pelo mercado em razão de exigências de processos mais sanos e de menor impacto ambiental, como é o caso do denominado "boi verde", um animal alimentado apenas com pastagem, que se caracteriza como uma carne diferenciada daquela produzida por sistemas de confinamentos mantidos na maioria de outros países produtores de carne bovina. Tais aspectos fizeram com que o Brasil passasse a figurar como o país detentor dos maiores rebanhos comerciais do mundo em termos de bovinos, suínos e também no setor avícola (BRASIL, 2004b). A Figura 1 apresenta o crescimento dos rebanhos bovinos, suínos e avícolas no Brasil nos últimos anos.

Este crescimento não se apresenta diferente quando se analisa o mercado de produtos veterinários, o qual possui um forte relacionamento com o setor agropecuário. Este setor, nos últimos anos tem apresentado um crescimento de $18,47 \%$ entre os anos de 2002 e 2004 , sendo que as estimativas preliminares do ano de 2005 indicam um crescimento de $7 \%$ em relação ao faturamento verificado no ano de 2004. Em relação ao mercado mundial, a América Latina foi responsável no ano de 2003 por um faturamento de US\$1,39 bilhões, o que representava $11,1 \%$ do faturamento mundial. O Brasil no ano de 2005 obteve um faturamento de US\$ 615 milhões, o que representa aproximadamente $44 \%$ do mercado latinoamericano e 5\% do mercado mundial (SINDAN, 2006; WOOD MACKENZIE, 2006).

A Tabela 1, a seguir indica a distribuição mundial em termos de faturamento da indústria de produtos veterinários.

A Tabela 2 indica para o ano de 2004, a distribuição do mercado brasileiro de produtos veterinários, em termos de faturamento por espécie animal, sendo que para o ano de 2005 as estimativas preliminares, por espécies, indicam que produtos veterinários destinados aos bovinos representaram $58 \%$ do faturamento da indústria, seguidos pelo setor de aves com cerca de $20 \%$ do mercado, já o setor de suinocultura registrou crescimento com $8,2 \%$ do total, e para o segmento de pets, eqüinos, ovinos e caprinos o desempenho permaneceu estável ou com ligeiro crescimento (SINDAN, 2005).

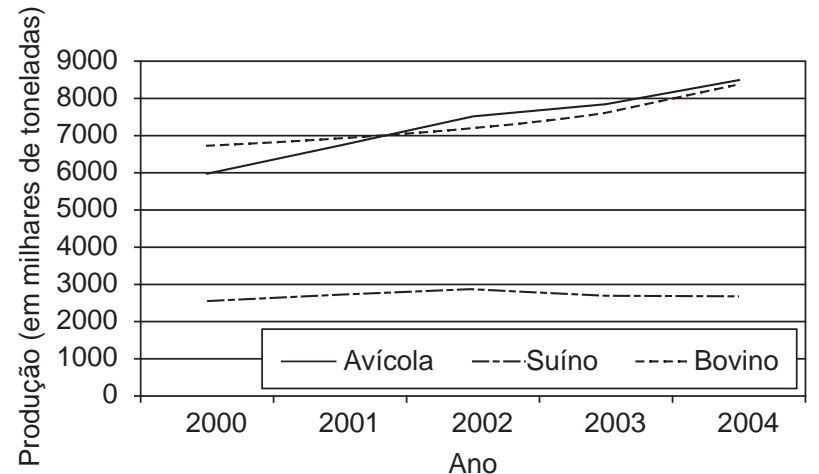

Figura 1. Crescimento do rebanho bovino, suíno e avícola nos últimos anos (ACSURS, 2006; MAPA, 2006; ORGANIZAÇÃO PAN AMERICANA DE SAÚDE, 2005).

Tabela 1. Faturamento da indústria veterinária mundial por região no ano de 2003. (WOOD MACKENZIE, 2006).

\begin{tabular}{lcc}
\hline \multicolumn{1}{c}{ Região } & $\begin{array}{c}\text { Faturamento } \\
\text { (bilhões de US \$) }\end{array}$ & Percentual (\%) \\
\hline América do Norte & 4,475 & 35,7 \\
Europa - Oeste & 3,640 & 29,0 \\
Extremo Oriente & 2,130 & 17,0 \\
América Latina & 1,390 & 11,1 \\
Europa - Leste & 0,535 & 4,3 \\
Outras regiões & 0,375 & 3,0 \\
Faturamento total & 12,545 & 100 \\
\hline
\end{tabular}

Tabela 2. Faturamento da indústria veterinária brasileira no ano de 2004 por segmento de espécies (SINDAN, 2005).

\begin{tabular}{lcc}
\hline \multicolumn{1}{c}{ Espécie } & Faturamento (US\$) & Percentual (\%) \\
\hline Bovinos & $392.657 .402,44$ & 55,6 \\
Aves & $153.281 .162,73$ & 21,7 \\
Pets & $65.955 .983,76$ & 9,3 \\
Suínos & $54.851 .556,72$ & 7,8 \\
Ovinos e caprinos & $21.190 .944,16$ & 3,0 \\
Eqüinos & $18.585 .629,58$ & 2,6 \\
Faturamento total & $706.522 .679,39$ & 100 \\
\hline
\end{tabular}

\section{Aspectos relativos à evolução do conceito de good manufacturing practices}

Em 1905, com a publicação do livro "The Jungle", de autoria de Upton Sinclair, foram abordadas as precárias condições sanitárias, nas quais animais eram abatidos e processados pela indústria frigorífica do Estado americano de Chicago, causando na época impacto e despertando a atenção da opinião pública sobre o assunto de higiene e controle sanitário de produtos alimentícios. Esta mobilização fez com que o congresso norte-americano instituísse, em 1906, o Pure Food and Drug Act, 
o qual descriminava condições de controle sanitário, tornando também ilegal a venda de carnes e remédios fora de especificações ou com informações adulteradas. Em 1937, após a morte de 107 pessoas por envenenamento pela substância sulfanilamida, foi instituído o Federal Food, Drug and Cosmetic (FD\&C) Act, o qual passou a obrigar as empresas americanas a provar a segurança dos produtos antes de sua comercialização (IMMEL, 2001; FIOCCHI; MIGUEL, 2003).

Tais atos podem ser considerados como marcos reguladores das questões de sanidade alimentar, bem como da criação de mecanismos de controle das mesmas. No entanto, as preocupações em relação a aspectos de controle e sanidade de alimentos e bebidas nos EUA, datam desde o ano de 1862, quando foi criado o Departamento de Agricultura, que é considerado o ponto inicial do que se denomina hoje de FDA - food and drug administration, o qual foi autorizado em 1927 pelo Congresso Americano com a denominação de food, drug, and insecticide administration, sendo em 1930 abreviado para food and drug Administration (FOOD AND DRUG ADMINISTRATION, 2006).

Em termos mundiais, outros incidentes envolvendo morte de pessoas, bem como as ações implementadas para a criação de órgãos de controle e regulação do setor de alimentos e medicamentos, fizeram com que a Organização Mundial da Saúde (OMS) passasse a desenvolver um primeiro documento oficial sobre este tema, tendo o mesmo sido aprovado em 1968, e então difundido a todos os países membros da organização. Em 1969, a OMS oficialmente divulgou o que se denominava de good manufacturing practices (GMPs), as quais representavam naquele momento a opinião de um grupo de especialistas internacionais e não um critério próprio da organização. A partir de 1978 as GMPs passaram a ter aparato legal nos EUA, obrigando as empresas a verificarem tais recomendações sob pena de serem sancionadas caso não as seguissem. Desde então, as GMPs têm sido aperfeiçoadas e atualizadas, sendo que a partir de 1987 foi acrescida a letra C "Current", que pode ser entendida aqui como atual, para diferenciar a norma em vigor das antigas, passando a assumir a sigla CGMP - current goods manufacturing practices ou Atual Boas Práticas de Fabricação (IMMEL, 2001; FIOCCHI \& MIGUEL, 2003, PEREIRA FILHO; BARROCO, 2004).

O histórico das BPFs no Brasil é recente, sendo que as mesmas passaram a ter efeito legal por meio da Portaria n ${ }^{\circ}$ 16, de 06 março de 1995, em que a Secretaria de Vigilância Sanitária (SVS) do Ministério da Saúde determinava a todos os estabelecimentos produtores de medicamentos o cumprimento destas diretrizes. Em 19 de abril de 1999, foi criada pelo Ministério da Saúde, a Agência Nacional de Vigilância Sanitária (ANVISA), tendo seu modelo de trabalho baseado nas agências euro- péias e norte-americanas. Após a criação da ANVISA, verificou-se a necessidade de revisão e atualização das normas de inspeção vigentes, sendo então publicada em 13 de julho de 2001 a Resolução - RDC 134, a qual determinava que todos os fabricantes de medicamentos deveriam cumprir as diretrizes estabelecidas pelo regulamento técnico (BRASIL, 2001; FIOCCHI; MIGUEL, 2003; LARA; MOREIRA, 2003; ANVISA, 2004).

Especificamente no que se refere à indústria farmacêutica de produtos veterinários, o Ministério da Agricultura, Pecuária e Abastecimento (MAPA), considerando a necessidade de dispor de instrumento atualizado de avaliação das condições de fabricação e garantia de qualidade dos produtos de uso veterinário, estabeleceu por meio da Instrução Normativa $n^{\circ} 13$ de 03/10/2003 (BRASIL, 2003), o Regulamento de Boas Práticas de Fabricação de Produtos de Uso Veterinário, sendo que tal regulamento avaliado por meio da aplicação do Roteiro de Inspeção de Boas Práticas de Fabricação, que seria então elaborado e aplicado pela Coordenação de Fiscalização de Produtos Veterinários do Departamento de Defesa Animal.

Em 22 de abril de 2004, por meio da aprovação do Decreto $n^{\circ} 5053$ (BRASIL, 2004a), passou-se a regulamentar a fiscalização de produtos de uso veterinário e dos estabelecimentos que os fabricariam, manipulariam, fracionariam, envasariam, rotulariam, controlariam a qualidade, comercializariam, armazenariam, distribuiriam, importariam ou exportariam, ficando o MAPA responsável pela execução da inspeção e da fiscalização. De maneira geral se reconhece por meio da aplicação da BPF para o setor farmacêutico veterinário, que o gerenciamento da qualidade é o aspecto da função que determina e implementa a política da qualidade, isto é, as intenções e direções globais de determinado órgão relativas à qualidade, formalmente expressa e autorizada pela administração superior da empresa (BRASIL, 2003).

Dessa forma, um sistema de garantia da qualidade deve assegurar que todos os requisitos das BPF sejam cumpridos, em relação a: desenvolvimento, produção, controle de qualidade, definições de responsabilidades, realização dos controles necessários nas diferentes fases do processo produtivo, calibração de equipamentos, validação de processos, além de determinar um sistema de logística para garantir que os insumos e os medicamentos sejam armazenados, distribuídos e manuseados, de modo a garantir a qualidade durante todo o prazo de validade dos mesmos. Também é importante a realização de auto-inspeções regulares, que avaliem a efetividade e o cumprimento do sistema de garantia da qualidade (MORETTO, 2002; FIOCCHI; MIGUEL, 2003).

Outro aspecto relevante na BPF diz respeito ao enfoque dado aos treinamentos dos funcionários, os quais devem atender a diversos objetivos, dentre eles: redução de erros, envolvimento no trabalho, aumento de motivação, criação 
de capacidade de resolução e prevenção de problemas e melhor comunicação. Com isso é possível alcançar diversos benefícios, dentre eles: aumento da qualidade de produtos, aumento de produtividade, diminuição de retrabalho e rejeitados, redução de custos operacionais. (PEREIRA FILHO; BARROCO, 2004; VENERENDA, 2004).

Em relação ao aspecto de harmonização e compatibilização das BPFs com outras normas da qualidade, a Associação Brasileira de Normas Técnicas (ABNT) publicou a NBR 14919 intitulada: "Requisitos específicos para a aplicação da NBR ISO 9001 em conjunto com as Boas Práticas de Fabricação". Esta norma objetiva servir de respaldo oficial às empresas, sendo que muitas já passaram a adotar um sistema de gestão da qualidade baseado na conciliação destas duas normas. (ABNT, 2002; MACEDO, 2003).

\section{Método e procedimentos delineadores da pesquisa}

Os resultados apresentados neste trabalho foram obtidos por meio de uma pesquisa realizada no ano de 2005, e que teve como objetivo geral a verificação da utilização do sistema da qualidade BPF (Boas Práticas de Fabricação) como um sistema de gestão da qualidade em empresas fabricantes de produtos veterinários. Foram levantadas também as dificuldades verificadas nos itens relativos à sua implementação, principalmente aqueles que se referiam ao porte da empresa, aos recursos a serem despendidos, à cultura de gestão da qualidade já existente, à capacitação técnica requerida, e a outros aspectos.

Por se tratar de uma legislação recente, verificou-se também em que estágio de implementação das BPFs se encontravam as empresas, e se estas estavam adotando a mesma como o modelo orientativo de seu sistema da qualidade.

O método de pesquisa empregado na coleta de dados foi pesquisa de campo do tipo survey. Este tipo de pesquisa estuda a amostra de uma população por meio da coleta de dados de forma individual. Neste tipo de pesquisa empregam-se como técnicas de coleta de dados: entrevistas pessoais; entrevistas via telefone; entrevistas via correspondência por correio; e mais recentemente via questionário por e-mail (BACHMANN et al., 1999; FORZA, 2002; GRANELLO; WHEATON 2004).

A pesquisa tipo survey, como pesquisa de campo, pode ser descritiva, exploratória ou experimental, sendo que no presente caso verificaram-se quantitativamente as dificuldades relativas à implantação do Sistema BPF pelas empresas, ampliando e aprofundando o conhecimento existente, sendo, portanto, classificada como uma pesquisa de campo do tipo exploratória. A verificação do instrumento de pesquisa (questionário) se deu por meio da realização de pré-testes que foram submetidos a distintos profissionais relacionados às atividades de gestão da produção em empresa do setor farmacêutico, e também atividades acadêmicas e de consultoria em áreas afins (YIN, 2001; LAKATOS; MARCONI, 2002).

A condução da coleta de dados se deu com as empresas cadastradas no setor junto ao SINDAN (Sindicato Nacional da Indústria de Produtos para Saúde Animal), constando 99 empresas cadastradas em meados de 2005 (SINDAN, 2004).

A condução da pesquisa junto às empresas seguiu as etapas descritas no cronograma apresentado na Tabela 3.

Durante a etapa de envio das mensagens às empresas, verificou-se que 7 das empresas cadastradas não possuíam e-mail, sendo reduzido para 92 o número de empresas pesquisadas. A Tabela 4 a seguir apresenta de

Tabela 3. Planejamento para execução da coleta de dados.

\begin{tabular}{clc}
\hline Etapa & \multicolumn{1}{c}{ Procedimento } & $\begin{array}{c}\text { Período de espera } \\
\text { por resposta }\end{array}$ \\
\hline $1^{\text {a }}$ & $\begin{array}{l}\text { Envio por e-mail da carta de } \\
\text { apresentação da pesquisa, } \\
\text { junto com o questionário a ser } \\
\text { preenchido } \\
2^{\text {a }} \quad \begin{array}{l}\text { Envio por e-mail de mensagem } \\
\text { de lembrança sobre o questio- } \\
\text { nário enviado }\end{array}\end{array}$ & 1 semana \\
$3^{\text {a }} \quad \begin{array}{l}\text { Envio de última mensagem de } \\
\text { lembrança sobre o questionário } \\
\text { enviado }\end{array}$ & 1 semana \\
$4^{\text {a }}$ & $\begin{array}{l}\text { Envio de mensagem de agrade- } \\
\text { cimento às empresas respon- } \\
\text { dentes }\end{array}$ & 1 dia \\
\hline &
\end{tabular}

Tabela 4. Grau de resposta nas etapas de coleta de dados.

\begin{tabular}{lccccc}
\hline Etapa & $\begin{array}{c}\text { Total de e-mails } \\
\text { enviados }\end{array}$ & $\begin{array}{c}\text { Questionários } \\
\text { respondidos completos }\end{array}$ & $\begin{array}{c}\text { Questionários } \\
\text { respondidos em branco }\end{array}$ & $\begin{array}{c}\text { E-mails falhos } \\
\text { Capacidade } \\
\text { excedida }\end{array}$ & $\begin{array}{c}\text { Endereço } \\
\text { inexistente }\end{array}$ \\
\hline $1^{\text {a }}$ & 92 & 2 & 0 & 3 & 18 \\
$2^{\text {a }}$ & 90 & 4 & 5 & 0 & 69 \\
$3^{\text {a }}$ & 81 & 4 & 8 & 0 & 18 \\
Total & 92 & 10 & 13 & - & 18 \\
\hline
\end{tabular}


forma sucinta as taxas de retorno verificadas durante a fase de coleta de dados, constatando uma taxa de $25 \%$ de retorno dos questionários, sendo $10,8 \%$ de questionários respondidos, e 14,1\% de questionários em branco, estando esta porcentagem de retorno qualificada como aceitável para este tipo de pesquisa, segundo a literatura da área (BACHMANN et al., 1999).

\section{Discussão e análise dos principais resultados verificados na pesquisa}

A seguir serão apresentados e discutidos alguns dos principais resultados obtidos, abordando-se os seguintes tópicos da pesquisa: caracterização econômica das empresas pesquisadas; aspectos motivadores; e expectativas para implementação das BPFs. Serão descritos também os aspectos dificultadores na implementação das BPFs, bem como os benefícios da implementação das BPFs e o desdobramento sobre outras ferramentas da qualidade.

\subsection{Caracterização econômica das empresas pesquisadas}

Em uma primeira etapa, procurou-se caracterizar o perfil dos respondentes do questionário para avaliar a inerência e conhecimento com o tema da pesquisa. Verificou-se pelos resultados obtidos, que os respondentes da pesquisa em sua ampla maioria ocupavam cargos de elevada responsabilidade dentro da empresa e/ou atuavam em áreas diretamente relacionadas ao tema da pesquisa, o que reforça e valoriza o conteúdo das informações obtidas. O perfil em relação ao cargo ocupado na empresa pelos respondentes da pesquisa indica, assim, uma predominância de cargos de responsabilidade técnica (veterinários, farmacêuticos, químicos, e outros) e direção (gerentes e diretores), com atuação em áreas relacionadas à Produção, Administração, Qualidade e Processos, podendo tais dados serem visualizados na Figura 2.

Em relação à estratificação do porte das empresas participantes da pesquisa, foi considerado como aspecto classificador o faturamento alcançado no ano de 2005 , sendo dessa forma classificadas como: micro, pequena, média e grande empresa. Pela Figura 3, pode-se verificar que as empresas respondentes se enquadravam da seguinte maneira: $31 \%$ empresas de pequeno porte, $38 \%$ empresas de médio porte, e outros $31 \%$ como empresas de grande porte. Esta classificação é importante, já que os porcentuais entre os portes das empresas apresentamse próximos e ajudam a validar os resultados a serem discutidos no tópico de análise de correlação, descrito no item 5.5.

Considerando a natureza dos produtos veterinários fabricados por estas empresas, verificou-se que $60 \%$ das

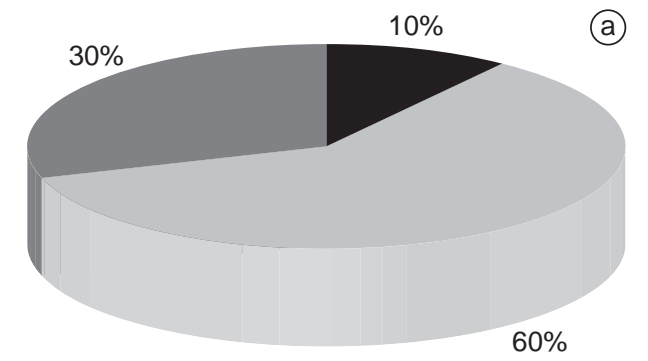

Gerente $\square$ Diretor $\square$ Responsável técnico

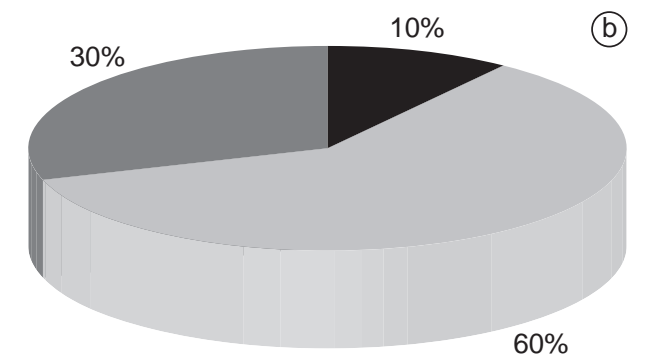

Produção $\square$ Administrativa

Qualidade e processos

Figura 2. Cargo e área de atuação dos respondentes. a) cargo; e b) área de atuação.

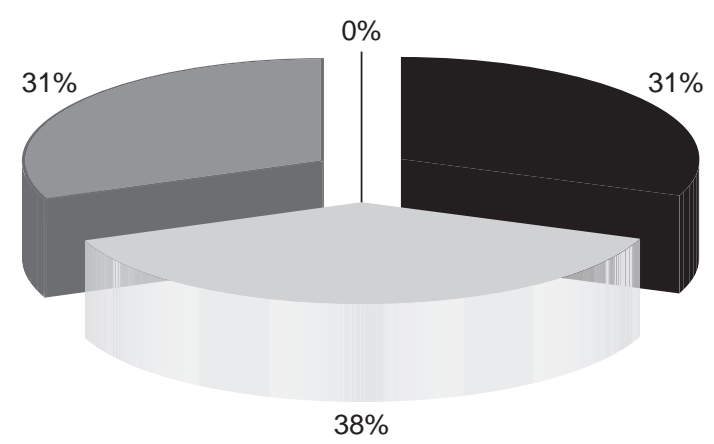

$\square$ Inferior ou igual a $\mathrm{R} \$ 244.000,00$ (Microempresa)

De $R \$ 244.000,00$ a $R \$ 1.200 .000,00$ (Pequena empresa) $\square$ De R\$ $1.2000 .000,00$ a R\$ 20.000.000,00 (Média empresa)

Acima de $\mathrm{R} \$ 20.000 .000,00$ (Grande porte)

Figura 3. Porte da empresa em função do faturamento anual.

mesmas classificavam-se como fabricantes de produtos farmacêuticos, $25 \%$ como fabricantes de produtos biológicos, e $15 \%$ como fabricantes de produtos farmoquímicos. Este tipo de classificação, que considera a natureza de produtos fabricados é relevante no aspecto das exigências legais e técnicas estabelecidas para cumprimento e adequação das BPFs pelas empresas. 


\subsection{Aspectos motivadores e expectativas para implementação das BPFs}

Verificou-se em relação às empresas pesquisadas que $92 \%$ das empresas já tinham iniciado a implantação das BPFs, enquanto que o restante, $8 \%$ das empresas, não tinham ainda iniciado, mas pretendiam implantá-la. Este dado indica que apesar de ser uma exigência legal recente para a indústria veterinária brasileira, segundo a Instrução Normativa $\mathrm{n}^{\circ} 13$ do MAPA, a grande maioria das empresas já tinha se antecipado a esta decisão.

Estes e outros aspectos foram melhor discriminados junto às empresas ao se pesquisar os motivos que tinham levado a empresa a implantar o sistema BPF, sendo tais dados ilustrados na Figura 4. Cabe ressaltar, que nesta etapa da pesquisa (caracterizada desde a seção 5.2 até 5.4) permitiu-se no questionário que as empresas respondentes assinalassem mais de uma alternativa.

Pode-se verificar que a totalidade das empresas pesquisadas indicou que aspectos relativos a melhor gestão da qualidade em termos organizacionais, de processos e do produto final tinham sido o principal motivador na implantação das BPFs. Outros aspectos citados como relevantes foram: a obrigação da legislação vigente e a melhoria da imagem da empresa, citados por $83 \%$ das empresas pesquisadas. Ao contrário, aspectos relacionados à exigência dos clientes e concorrentes já certificados, citados por $55 \%$ das empresas pesquisadas, figuram como itens menos motivadores na implantação das BPFs.

Procurou-se também verificar o estágio em que se encontravam as empresas que já tinham iniciado a implementação das BPFs. Para a pesquisa foram definidas quatro etapas ou níveis de implantação, sendo verificados os seguintes resultados:

a) $8 \%$ das empresas respondentes afirmaram que se encontravam em um estágio inicial, definido nesta pesquisa como de definição da política e objetivos da qualidade na empresa;

b) $58 \%$ das empresas se classificavam como em um estágio intermediário, ou seja, se encontravam na fase de elaboração da documentação geral, como: manual da qualidade, procedimentos e instruções de trabalho;

c) $17 \%$ das empresas declararam estar em um estágio final de implementação das BPFs, estando já implementando os procedimentos e instruções definidos; e

d) $17 \%$ das empresas se classificavam como tendo o sistema BPF totalmente implementado.

Outro aspecto pesquisado, refere-se à verificação da expectativa das empresas em relação ao tempo que foi ou seria demandado até a efetiva implementação das BPFs nestas empresas. Este aspecto é relevante, pois indica de certa forma com que ritmo as empresas estariam dispostas a disponibilizar recursos econômicos e físicos para o atendimento das questões legais exigidas pelo MAPA. Verificou-se em relação às empresas que já tinham o sistema BPFs totalmente implementado, que $50 \%$ das mesmas tinham despendido de 12 a 24 meses, enquanto que as outras $50 \%$ despenderam mais de 36 meses para implementar as BPFs. Das empresas que ainda estavam nas fases de implementação das BPFs, as expectativas de ter o sistema totalmente implementado eram de 12 a 24 meses para $40 \%$ das empresas; 25 a 36 meses para $50 \%$ das empresas; e acima de 36 meses para $10 \%$ das empresas.

\subsection{Aspectos dificultadores na implementação das BPFs}

A expectativa verificada das empresas atenderem as exigências das BPFs em um período de médio a longo prazo denota dificuldades inerentes a um processo que na maioria das vezes implica em mudanças da cultura

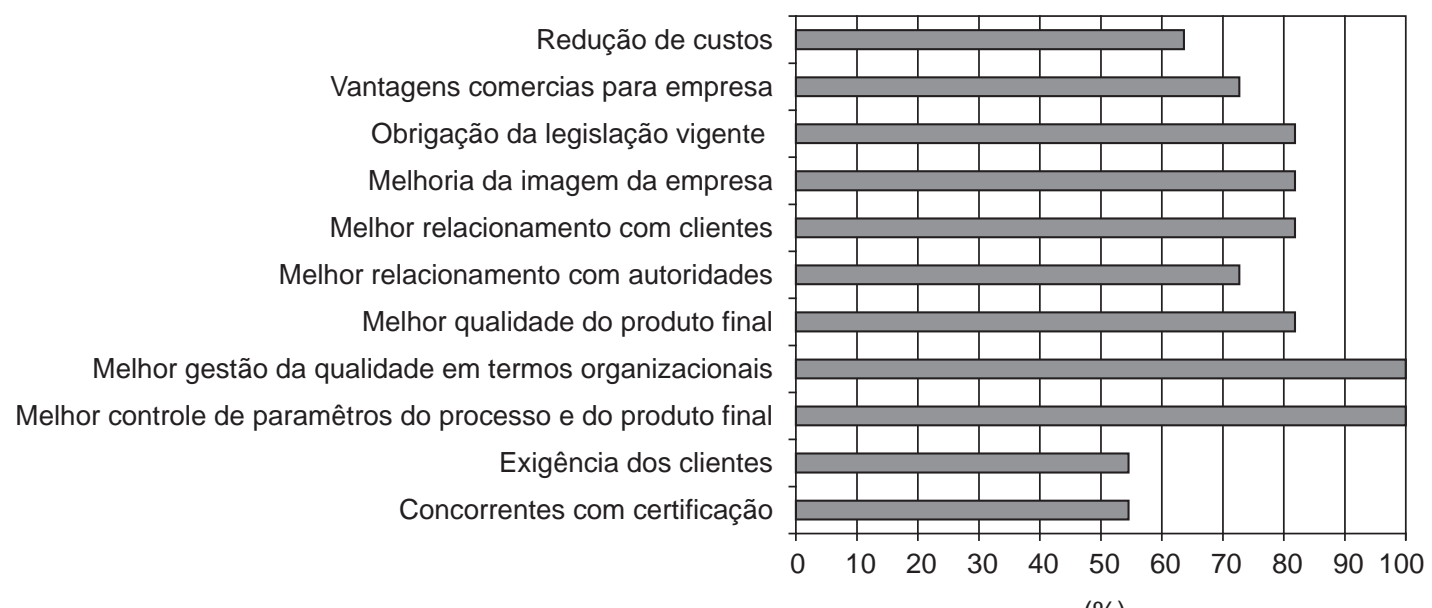

(\%)

Figura 4. Aspectos motivadores para a implantação do sistema BPF. 
organizacional, bem como restrições de ordem financeira e/ou técnica que a empresa deverá superar.

Dessa forma, procurou-se verificar junto às empresas pesquisadas quais as principais dificuldades que as mesmas tinham enfrentado ou estavam enfrentando em relação à implementação das BPFs, considerando três abordagens principais: organizacional, tecnológica e financeira.

Considerando a abordagem organizacional, verificouse que os aspectos relacionados ao desconhecimento da força de trabalho sobre o sistema BPF (83\%) e o pequeno número de funcionários dedicados ao desenvolvimento dos trabalhos (67\%), foram os mais citados pelas empresas pesquisadas. Tais aspectos são característicos na implantação de sistemas de qualidade que podem estar sujeitos à certificação ou auditorias, pois a força de trabalho da empresa deve ter um conhecimento das normas, procedimentos e instruções de trabalho definidas, implicando em significativos esforços de conscientização e treinamento. Como se verifica um aumento da carga de trabalho em atividades relacionadas à implantação destes sistemas da qualidade, a força de trabalho convive durante estes períodos com um acúmulo de atividades e tarefas. Em contrapartida, aspectos relacionados ao entendimento da norma, elaboração da documentação requerida, treinamentos insuficientes, e baixo envolvimento da alta administração foram citados por apenas $24 \%$ das empresas como fatores dificultadores na implementação das BPFs. A Figura 5 a seguir ilustra estes dados.

No tocante à abordagem tecnológica, o principal aspecto dificultador citado pelas empresas foi a obsolescência dos equipamentos (45\%). Uma possível causa deste aspecto verificado junto a alguns respondentes da pesquisa, é que parte das empresas do ramo veterinário apresenta um parque fabril antiquado para o pleno atendimento das novas exigências legais, principalmente no que tange ao controle da qualidade e à validação de seus processos produtivos. Este fator é reforçado pelo segundo grupo citado com maiores dificuldades na implantação das BPFs, e que figuram com $33 \%$ das respostas: instalações físicas da empresa inadequadas, dificuldades na validação de processos, e dificuldades na aquisição de equipamentos laboratoriais. A Figura 6 ilustra estes dados.

Considerando a abordagem financeira, importante fator na tomada de decisões de investimento pelas empresas do segmento, verifica-se o aspecto mais citado pelas empresas, ou seja, a priorização de investimentos em setores não ligados às BPFs $(50 \%)$. Este fato indica que talvez o problema não seja de ordem financeira, mas sim da ausência de um melhor planejamento estratégico das empresas, pois este porcentual demonstra um grau de descontentamento e/ou falta de percepção por parte dos respondentes de que os recursos destinados à implantação das BPFs são adequados para a condução das tarefas planejadas. Em segundo lugar, na escala de aspectos financeiros citados como de maior dificuldade, situamse os citados com mesmo percentual de $25 \%$ : alto custo de equipamentos, alto custo de consultorias, e alto custo implantação. Tais aspectos são inerentes aos processos de implantação de sistemas de qualidade, principalmente quando tais sistemas são passíveis de auditorias externas, o que demanda a necessidade de um apoio de consultoria durante as fases de implantação e certificação. A Figura 7 ilustra estes dados.

\subsection{Aspectos benéficos advindos da implementação das BPFs e desdobramentos sobre outras ferramentas da qualidade}

Esta parte da pesquisa caracterizou-se pela convergência de opinião das empresas respondentes em relação aos principais benefícios advindos das BPFs, considerando o estágio em que as mesmas se encontravam na

Instrução e treinamento da força de trabalho insuficientes

Envolvimento de apenas parte da alta administração da empresa

Dificuldade na elaboração de rotinas

Dificuldade na elaboração da documentação exigida

Dificuldade de entendimento da norma

Dificuldade no controle da documentação

Desconhecimento dos funcionários do Sistema BPF

Número reduzido de funcionários, frente ao elevado volume de trabalho

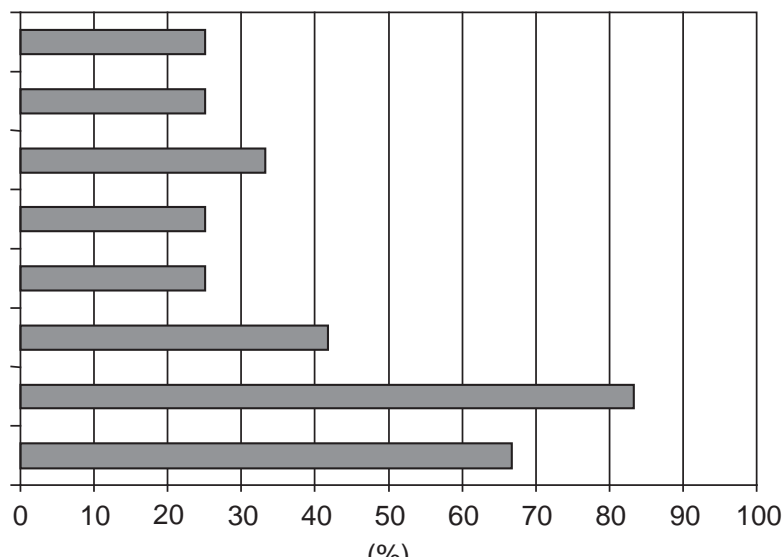

(\%)

Figura 5. Principais dificuldades organizacionais citadas na implantação do sistema BPF. 
sua implementação. Verificou-se que a totalidade das empresas indicou que houve melhoria no ambiente organizacional, envolvendo fatores relacionados à organização, ao treinamento, à motivação, e ao envolvimento da força de trabalho nas empresas. Outros benefícios citados por $92 \%$ das empresas foram: aumento da qualidade dos

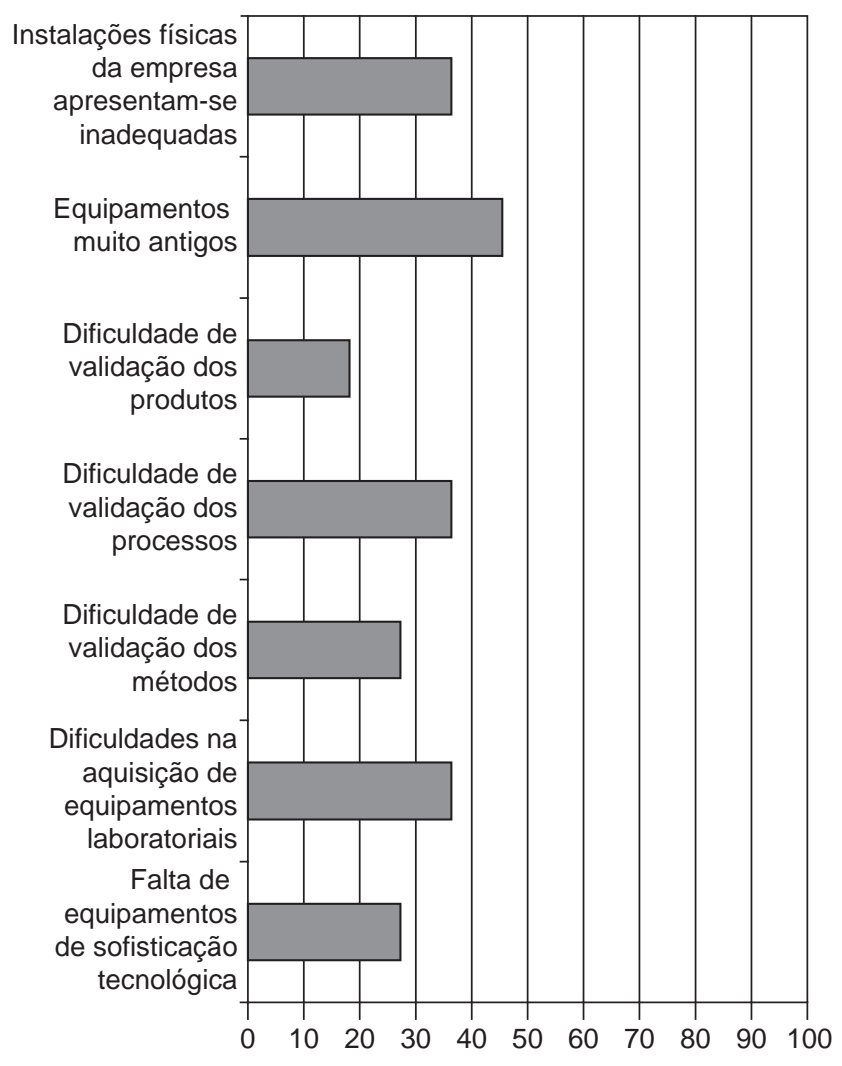

(\%)

Figura 6. Principais dificuldades tecnológicas citadas na implantação do sistema BPF.

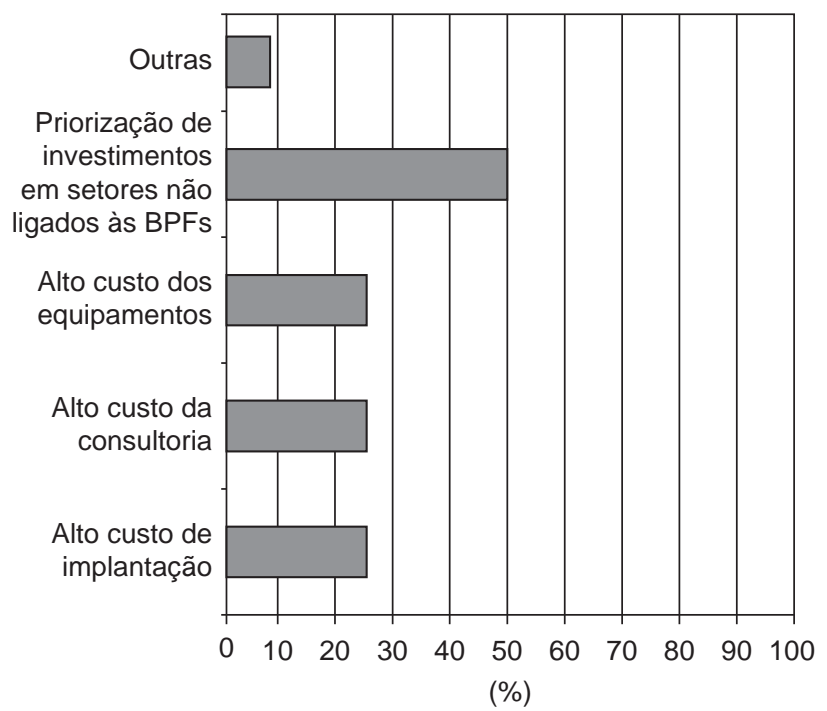

Figura 7. Principais dificuldades financeiras para implantação do sistema BPF. produtos, redução dos custos operacionais, e melhoria da imagem da empresa. Estes benefícios citados refletem um reconhecimento de aspectos importantes relacionados a produtos, processos e negócios das empresas, constituindo importantes alavancadores da gestão da qualidade e competitividade nas organizações. Os demais benefícios citados foram: diminuição de perdas e retrabalhos (84\%) e redução de reclamações dos produtos $(75 \%)$, os quais contemplam uma abordagem das empresas voltada ao cliente. A Figura 8 ilustra estes dados.

Outro aspecto também verificado, por se tratar de um mecanismo de melhoria contínua, e também por ser uma exigência das BPFs, diz respeito à prática de auditorias internas de avaliação do sistema da qualidade, constatando-se que todas as empresas pesquisadas têm esta prática implementada, sendo conduzida com frequiências distintas, a saber: 3 meses (50\% das empresas), 06 meses (10\% das empresas), 12 meses (30\% das empresas), outro período (10\% das empresas). A grande maioria destas empresas (92\%) adota para a condução destas auditorias internas a constituição de equipes de auditores internos designados pela alta administração, sendo que apenas $8 \%$ das empresas contratam auditores externos para a condução das auditorias.

Um último tópico abordado pela pesquisa buscou avaliar se as empresas tinham outras ferramentas e/ou técnicas de gestão da qualidade ou melhoria de produtividade implementada, pois este aspecto denotaria um background destas empresas em programas de melhoria da qualidade e produtividade, bem como a adequação e compatibilização das BPFs com estes programas. Foi verificado que $42 \%$ das empresas possuem outras ferramentas e/ou técnicas de melhoria da qualidade e produtividade, o que denota

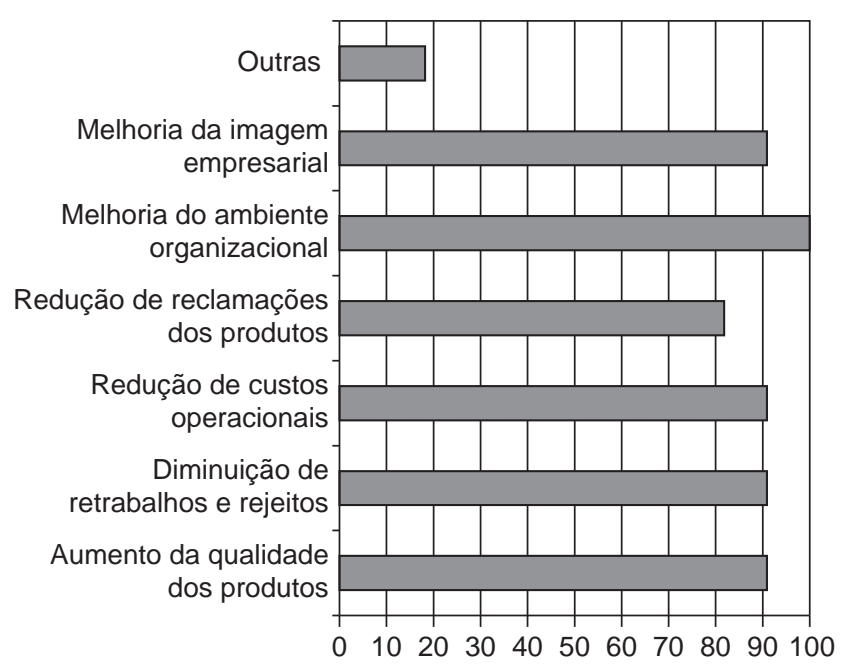

(\%)

Figura 8. Melhorias advindas da implantação do sistema BPF. 
que a maioria das empresas pesquisadas está conduzindo as BPFs como sistema principal de gestão da qualidade e produtividade. Das empresas que responderam possuir outras ferramentas e/ou técnicas de gestão da qualidade e produtividade, foram mais citadas: just in time (técnica praticada por $60 \%$ destas empresas); Controle Estatístico de Processo - CEP (sistema praticado por $40 \%$ destas empresas); total productive maintenance - TPM (praticado por $40 \%$ destas empresas); Programa 5S (praticado por 40\% destas empresas); Sistema ISO 9000:2000 (praticado por 20\% destas empresas); Ciclo PDCA (praticado por $20 \%$ destas empresas); outras ferramentas e/ou técnicas (praticadas por $20 \%$ destas empresas). Uma análise preliminar que se pode fazer destes dados, considerando-se o número total de empresas pesquisadas, é que ainda é incipiente a prática de ferramentas consideradas como básicas de melhorias da qualidade, tais como PDCA, 5S e CEP. Outro aspecto verificado é que as empresas que adotam outros sistemas assim o fazem primordialmente para diminuir seus estoques, melhorar seu desempenho produtivo e de entregas ao cliente (sistema JIT), do que em busca de certificação de sistemas da qualidade (ISO 9000:2000).

\subsection{Análise de correlação existente entre os tópicos pesquisados}

A análise de correlação permite examinar relações de interesse entre duas variáveis, por meio da relação linear entre duas variáveis quantitativas, que resulta em um coeficiente de correlação (r), o qual pode apresentar-se com valor positivo, quando as variáveis analisadas estão positivamente relacionadas; com valor negativo, quando há uma correlação negativa entre as variáveis; e com valor nulo, indicando que não existe nenhuma correlação entre as variáveis analisadas (HOFFMAN, 2006).

O coeficiente de correlação entre as variáveis analisadas foi estimado com o auxílio do pacote estatístico R. Em uma primeira etapa, verificou-se a existência ou não de inter-relação entre os aspectos avaliados, como, por exemplo, entre fatores motivadores para implantação do Sistema BPF e aspectos dificultadores operacionais. Os resultados obtidos foram pouco expressivos, ou seja, os coeficientes se apresentaram pequenos $(r<0,7)$, demonstrando uma baixa correlação entre os diversos tópicos.

Em uma segunda etapa, a análise da correlação entre as variáveis contemplou a existência de inter-relações entre o porte das empresas respondentes e os tópicos avaliados na pesquisa (aspectos motivacionais, dificuldades organizacionais, tecnológicas e financeiras, e benefícios advindos da implantação).

A Tabela 5 apresenta os coeficientes de correlação entre os aspectos motivacionais para implantação das BPFs e o porte das empresas.

A partir da análise dos coeficientes de correlação da Tabela 5, é possível notar que as empresas de pequeno porte buscam realizar a implantação das BPFs, principalmente devido às melhorias no relacionamento com os clientes, na qualidade do produto final, no controle de parâmetros do processo, e na gestão da qualidade em termos organizacionais. À medida que o porte da empresa aumenta, as empresas deixam de procurar a implantação das BPFs por estes motivos, e passam a fazê-lo principalmente por exigência dos clientes, vantagem comercial, melhoria da imagem, e concorrentes já certificados.

A Tabela 6 apresenta os coeficientes de correlação entre os aspectos dificultadores e o porte das empresas.

A análise das dificuldades organizacionais permite verificar que as empresas de pequeno porte enfrentam maiores problemas, principalmente no que diz respeito ao desconhecimento dos funcionários sobre o sistema BPF, ao baixo envolvimento da alta administração e à insuficiência de instrução e treinamento da força de trabalho. Já para as empresas de médio porte as dificuldades no controle de documentação, na elaboração de rotinas, e na elaboração da documentação exigida são os aspectos que se destacam. E por fim, para as empresas de grande porte, a dificuldade no entendimento da norma representa o principal item dificultador.

Em relação às dificuldades tecnológicas, estas aparecem em destaque nas empresas de médio e grande porte. Para as empresas de médio porte, itens como a falta de equipamentos de sofisticação tecnológica, a dificuldade na aquisição de equipamentos laboratoriais e os equipamentos fabris antigos, apresentaram-se com maior destaque. Já para as empresas de grande porte, as prin-

Tabela 5. Coeficiente de correlação entre tópicos avaliados e porte das empresas respondentes.

\begin{tabular}{|c|c|c|c|}
\hline \multirow[b]{2}{*}{ Motivos da implantação } & \multicolumn{3}{|c|}{ Porte das Empresas } \\
\hline & Pequena & Média & Grande \\
\hline $\begin{array}{l}\text { Melhor relacionamento com } \\
\text { clientes }\end{array}$ & 0,49 & 0,03 & $-0,48$ \\
\hline $\begin{array}{l}\text { Melhor qualidade do produto } \\
\text { final }\end{array}$ & 0,41 & $-0,12$ & $-0,25$ \\
\hline $\begin{array}{l}\text { Melhor controle de parâmetros } \\
\text { do processo e do produto final }\end{array}$ & 0,26 & $-0,08$ & $-0,16$ \\
\hline $\begin{array}{l}\text { Melhor gestão da qualidade em } \\
\text { termos organizacionais }\end{array}$ & 0,26 & $-0,08$ & $-0,16$ \\
\hline Redução de custos & 0,19 & $-0,17$ & 0,00 \\
\hline $\begin{array}{l}\text { Obrigação da legislação } \\
\text { vigente }\end{array}$ & 0,10 & 0,03 & $-0,12$ \\
\hline $\begin{array}{l}\text { Melhor relacionamento com } \\
\text { autoridades }\end{array}$ & 0,10 & 0,03 & $-0,12$ \\
\hline $\begin{array}{l}\text { Melhoria da imagem da } \\
\text { empresa }\end{array}$ & 0,00 & $-0,12$ & 0,13 \\
\hline $\begin{array}{l}\text { Vantagens comerciais para a } \\
\text { empresa }\end{array}$ & 0,00 & $-0,12$ & 0,13 \\
\hline Concorrentes com certificação & $-0,10$ & $-0,03$ & 0,12 \\
\hline Exigência dos clientes & $-0,10$ & $-0,37$ & 0,48 \\
\hline
\end{tabular}


Tabela 6. Coeficientes de correlação entre aspectos dificultadores e porte das empresas.

\begin{tabular}{|c|c|c|c|c|}
\hline & & \multicolumn{3}{|c|}{ Porte das Empresas } \\
\hline & & Pequena & Média & Grande \\
\hline \multirow[t]{7}{*}{ Dificuldade organizacional } & Desconhecimento dos funcionários do sistema BPF & 0,33 & $-0,29$ & 0,00 \\
\hline & Envolvimento de apenas parte da alta administração da empresa & 0,11 & $-0,10$ & 0,00 \\
\hline & Instrução e treinamento insuficientes da força de trabalho & 0,11 & $-0,10$ & 0,00 \\
\hline & Dificuldade no controle da documentação & 0,00 & 0,12 & $-0,13$ \\
\hline & Dificuldade na elaboração de rotinas & 0,00 & 0,12 & $-0,13$ \\
\hline & Dificuldade de entendimento da norma & $-0,26$ & 0,08 & 0,16 \\
\hline & Dificuldade na elaboração da documentação exigida & $-0,33$ & 0,29 & 0,00 \\
\hline \multirow[t]{7}{*}{ Dificuldade tecnológica } & Instalações físicas da empresa apresentam-se inadequadas & 0,00 & $-0,24$ & 0,25 \\
\hline & Equipamentos muito antigos & $-0,10$ & 0,31 & $-0,24$ \\
\hline & Dificuldade de validação dos produtos & $-0,26$ & 0,08 & 0,16 \\
\hline & Dificuldade de validação dos processos & $-0,33$ & 0,29 & 0,00 \\
\hline & Falta de equipamentos de sofisticação tecnológica & $-0,33$ & 0,68 & $-0,41$ \\
\hline & Dificuldade de validação dos métodos & $-0,41$ & 0,12 & 0,25 \\
\hline & Dificuldades na aquisição de equipamentos laboratoriais & $-0,41$ & 0,48 & $-0,13$ \\
\hline \multirow[t]{4}{*}{ Dificuldade financeira } & Alto custo da consultoria & 0,26 & 0,08 & $-0,32$ \\
\hline & Alto custo de implantação & 0,11 & 0,29 & $-0,41$ \\
\hline & Priorização de investimentos em setores não ligados às BPFs & $-0,19$ & 0,17 & 0,00 \\
\hline & Alto custo dos equipamentos & $-0,26$ & 0,53 & $-0,32$ \\
\hline
\end{tabular}

cipais dificuldades são encontradas na inadequação das instalações físicas e validações de métodos e produtos.

Quanto às dificuldades financeiras, aspectos relativos ao alto custo da consultoria e implantação apresentam-se como os principais fatores para as empresas de pequeno porte. Estes itens também são representativos para as empresas de médio porte, mas o alto custo dos equipamentos apresenta-se com maior destaque. Já para as empresas de grande porte não são verificados itens de grande destaque no que diz respeito às dificuldades financeiras.

Na Tabela 7 é apresentado o índice de correlação entre os benefícios obtidos com a implantação das BPFs e o porte das empresas.

Nota-se por meio da análise dos coeficientes de correlação, que quanto menor o porte da empresa, maior é o ganho em qualidade dos produtos; diminuição de retrabalhos e de custos operacionais; e a melhoria do ambiente organizacional devido à implantação das BPFs. O principal benefício para as grandes empresas, além da melhoria do ambiente organizacional, é a melhora da imagem empresarial.

\section{Considerações finais e principais conclusões}

A competitividade a que muitas empresas estão sujeitas nos dias atuais, tem feito com que as mesmas busquem desenvolver vantagens competitivas que as possibilitem obter sucesso em seus mercados de atuação. Uma
Tabela 7. Coeficientes de correlação entre benefícios da implantação das BPFs e o porte das empresas.

\begin{tabular}{lccc}
\hline & \multicolumn{3}{c}{ Porte das empresas } \\
\cline { 2 - 4 } Benefícios da implantação & Pequena & Média & Grande \\
\hline $\begin{array}{l}\text { Aumento da qualidade } \\
\text { dos produtos }\end{array}$ & 0,26 & $-0,08$ & $-0,16$ \\
$\begin{array}{l}\text { Diminuição de retrabalhos } \\
\text { e rejeitos }\end{array}$ & 0,26 & $-0,08$ & $-0,16$ \\
$\begin{array}{l}\text { Redução de custos } \\
\text { operacionais }\end{array}$ & 0,26 & $-0,08$ & $-0,16$ \\
$\begin{array}{l}\text { Melhoria do ambiente } \\
\text { organizacional }\end{array}$ & 0,17 & $-0,36$ & 0,21 \\
$\begin{array}{l}\text { Redução de reclamações } \\
\text { dos produtos }\end{array}$ & $-0,11$ & 0,10 & 0,00 \\
$\begin{array}{l}\text { Melhoria da imagem } \\
\text { empresarial }\end{array}$ & $-0,26$ & $-0,08$ & 0,32 \\
\hline
\end{tabular}

destas vantagens fundamenta-se no controle e gestão da qualidade, estando relacionada a requisitos de produtos, processos, gestão organizacional, atendimento aos clientes e avaliação de fornecedores. O atendimento de aspectos mínimos destes requisitos em alguns segmentos industriais tem sido tanto uma exigência de regulamentação e legislação governamental, como também um aspecto impulsionador de melhorias da qualidade e produtividade nas empresas. Esta survey conduzida com empresas fabricantes de produtos veterinários no Brasil, indicou estas preocupações por parte das empresas participantes da pesquisa, bem como mostrou estruturação por parte destas para a implementação das BPFs. Por se tratar de uma pesquisa de campo do tipo exploratória, os dados não 
podem ser generalizados para todo o setor de empresas fabricantes de produtos veterinários no Brasil, sendo esta uma limitação metodológica desta pesquisa. No entanto, alguns dados importantes podem ser extraídos, dentre os quais se destacam: todas as empresas pesquisadas já implantaram, estão implantando ou pretendem implantar as BPFs, tendo como principal fator motivador a melhoria da gestão da qualidade de processos, de produtos e organizacional; ao invés de um mero atendimento da legislação governamental. Outro fator verificado é que o período de implementação das BPFs nas empresas, segundo experiências e expectativas, variava de 12 a 36 meses. As dificuldades verificadas, no que diz respeito à implementação das BPFs, estavam associadas em sua maioria ao desconhecimento da força de trabalho das BPFs, o que denota uma necessidade maior de treinamento e conscientização dos funcionários. Outros aspectos verificados nesta pesquisa como principais melhorias advindas com a implementação das BPFs (melhoria de ambiente organizacional, qualidade dos produtos e imagem da empresa) são dados relevantes que denotam a importância das BPFs como procedimentos referenciais e delineadores na implementação dos sistemas de gestão da qualidade nas empresas fabricantes de produtos veterinários. Por fim, pode-se verificar por meio da análise de correlação, que o porte das empresas influencia nos resultados obtidos, seja no que diz respeito aos aspectos motivacionais para implementação do sistema BPF; seja nos aspectos dificultadores ou ainda nos benefícios advindos da implementação deste sistema de gestão e controle da qualidade.

\title{
The usage of the GMP (good manufacturing practices) quality management system for veterinary pharmaceutical industries
}

\begin{abstract}
The need to develop quality control and management methods has been faced as an improvement factor for the competitiveness and permanence of companies in their sectors. Nonetheless, in some industrial segments, this situation of quality control and management also occurs considering the demands for complying with governmental standards and legislations, such as the segment of industries manufacturing veterinary products in Brazil. This article intends to depict the main aspects and results which come from a survey research, which tried to analyze how veterinary product manufacturers have been adapted to the usage of Good Manufacturing Practices as a system of quality control and management. Due to collecting a bibliography, aspects relating to the context of agribusiness competitiveness and the market of veterinary products are described, as well as the main topics relating to standard procedures emphasized in Good Manufacturing Practices. The study was carried out as a survey in companies manufacturing veterinary products, attempting to characterize the methodology of the adopted research, as well as to report and analyze the collected data. The study concludes, among other aspects, that veterinary product manufacturers have been implementing Good Manufacturing Practices which are more encouraged by aspects which come from a more efficient management of their productive resources than by complying with governmental standards and legislations.
\end{abstract}

Keywords: Good manufacturing practices. GMP. Veterinary pharmaceutical industry. Quality management.

\section{Referências bibliográficas}

ACSURS - Associação dos criadores de suínos do Rio Grande do Sul. Evolução da suinocultura gaúcha e brasileira. Disponível em: <http://www.acsurs.com.br/Suinocultura\%20B rasileira.xls>. Acesso em: 30 mar. 2006.

ANVISA. Finalidade institucional. Disponível em: $<$ http://www. anvisa.gov.br/institucional/anvisa/apresentacao.htm $>$. Acesso em: 30 ago 2004.

ASSOCIAÇÃO BRASILEIRA DE NORMAS TÉCNICAS. NBR

14919: Sistema de gestão da qualidade - Setor Farmacêutico
- Requisitos para a aplicação da NBR ISO 9001:2000 em conjunto com as boas práticas de fabricação para a indústria farmacêutica (BPF). Rio de Janeiro, 2002.

BACHMANN, D. P.; ELFINK, J.; VANAZZA, G. E-mail and snail mail face off in research, Marketing Research, v. 11, n. 4, p. $10-15,1999$.

BRASIL. Agência Nacional de Vigilância Sanitária. ResoluçãoRDC N 134, 13 de jul. 2001. Diário Oficial da União, Brasília, 16 jul. 2001. 
Ministério da Agricultura, Pecuária e Abastecimento. Instrução Normativa $\mathbf{N}^{\mathbf{0}} \mathbf{1 3}, 03$ out. 2003. Diário Oficial da União, Brasília, 3 out. 2003.

Decreto $\mathrm{n}^{\circ}$ 5053, de 22 de abril de 2004. Aprova o regulamento de fiscalização de produtos de uso veterinário e dos estabelecimentos que os fabriquem ou comerciem, e dá outras providências. Diário Oficial da União, Brasília, 23 abr. 2004a.

Ministério da Agricultura, Pecuária e Abastecimento. Agronegócio brasileiro: uma oportunidade de investimentos. Disponível em: <http://www.agricultura.gov.br/portal/page?_ pageid=36,477071\&_dad=portal\&_schema=PORTAL $>$. Acesso em: 8 set. 2004b.

CGEE. Relatórios de Gestão do Centro de Gestão e Estudos Estratégicos 2002. Disponível em: <http://www.cgee.org.br/ sobre/relatorio2002.php>. Acesso em: 20 fev. 2006.

FIESP; CIESP. O sucesso da agroindústria: o que se pode aprender? Jul. 2004. Disponível em: <http://www.fiesp.com. $\mathrm{br} /$ publicacoes $/$ secao2/index.asp?id=530>. Acesso em: 7 out. 2004.

FIOCCHI, C. C.; MIGUEL, P. A. M. As dificuldades para a implantação da qualidade baseado nas Boas Práticas de Fabricação (BPF) em uma empresa de médio porte do setor farmacêutico: um estudo exploratório. In: ENCONTRO NACIONAL DE ENGENHARIA DE PRODUÇÃO, 23., 2003, Ouro Preto, MG, Brasil. Anais eletrônicos..., p. 1-8.

FOOD AND DRUG ADMINISTRATION. History of the FDA. Disponível em: <http://www.fda.gov/oc/history/historyoffda/ default.htm>. Acesso em: 24 jan. 2006.

FORZA, C. Surveys: survey research in operations management: a process-based perspective. International Journal of Operations \& Production Management, v. 22, n. 2, p. 152-194, 2002.

GRANELLO, D. H.; wheaton, j. e. Online data collection: strategies for research. Journal of Counseling and Development, v. 82, n. 4, p. 387-393, 2004.

HOFFMANN, R. Estatística para economista. São Paulo: Thomson, 4. ed., 2006

IMMEL, B. K. A brief history of the GMPs for pharmaceuticals. Pharmaceutical Technology North America, v. 25, n. 7, p. 44-49, 2001.

LAKATOS, E. M.; MARCONI, M. A. Técnicas de pesquisa: planejamento e execução de pesquisas, amostragens e técnicas de pesquisa, elaboração, análise e interpretação de dados. São Paulo: Atlas, 2002. 282 p.

LARA, V. C. D.; MOREIRA, R. A. Boas práticas de fabricação com foco no gerenciamento pela qualidade total. Fármacos \& Medicamentos, São Paulo, ano 4, n. 20, p. 36-44, 2003.

MACEDO, M. M. A integração das Boas Práticas de Fabricação (BPF) com a ISO 9001/00 na indústria farmacêutica. Fármacos \& Medicamentos, São Paulo, ano 4, n. 24, p.38-44, 2003.

MAKIYA, I.; ROTONDARO, R. G. Câmaras setoriais: Uma alavanca para o desenvolvimento da cadeia agroindustrial no Brasil. In: ENCONTRO NACIONAL DE ENGENHARIA DE PRODUÇÃO, 22., 2002, Curitiba, PR, Brasil. Anais eletrônicos..., p. 1-8.

MAPA - Ministério da Agricultura, Pecuária e Abastecimento. Estatística: Pecuária. Disponível em: <http://www.agricultura. gov.br/portal/page?_pageid=33,971401\&_dad=portal\&_ schema=PORTAL $>$. Acesso em: 01 abril, 2006.

MINISTÉRIO DA AGRICULTURA, PECUÁRIA E ABASTECIMENTO. Resultados da balança comercial do agronegócio brasileiro. Disponível em: <http:// www.agricultura.gov.br/pls/portal/docs/PAGE/MAPA/ BALANCA_COMERCIAL/NOTA_IMPRENSA_EDICOES_ ANTERIORES/2005\%20-\%202004.PDF>. Acesso em: 15 out. 2006.

MORETTO, R. H. Garantia da qualidade coordena Boas Práticas de Fabricação nas indústrias. Revista Controle de Contaminação, ano 5, n. 36, p. 12-23., 2002.

ORGANIZAÇÃO PAN AMERICANA DE SAÚDE. Perspectivas de erradicação da febre aftosa na América do Sul e seu reflexo no preço da arroba do boi. In: Seminário da marca OB, 3., 2005, Cuiabá, MT, Brasil. Disponível em: <http://bvs.panaftosa.org. br/textoc/Correa-Naranjo-FMD-arroba-boi-2005port.pdf $>$. Acesso em: 3 abril 2006.

PEREIRA FILHO, W. R.; BARROCO, R. Gestão da qualidade na indústria farmacêutica. In: OLIVEIRA, O. J. (org.) Gestão da qualidade: tópicos avançados. São Paulo: Thompson. cap.15. p.211-215., 2004.

PORTAL DO AGRONEGÓCIO. Uma oportunidade de investimento. Disponível em: <http://www. portaldoagronegocio.com.br/index.php?p=oportunidade $>$. Acesso em: 12 mar.2006.

SCALCO, A. R.; TOLEDO, J. C. Um modelo para gerenciar a qualidade na cadeia de produção do leite. In: ENCONTRO NACIONAL DE ENGENHARIA DE PRODUÇÃO, 22., 2002, Curitiba, PR, Brasil. Anais eletrônicos..., p. 1-8.

SINDAN. Associados. Disponível em: <http://www.sindan.org. br/osindan/associados.aspx>. Acesso em: 12 set. 2004.

Mercado veterinário 2004 por espécie animal. Disponível em: <http://www.sindan.org.br/informacoes/ mercado.aspx>. Acesso em: 25 nov. 2005.

Faturamento: mercado veterinário brasileiro. Disponível em: <http://www.sindan.org.br/informacoes/mercado.aspx>. Acesso em: 9 jan. 2006.

TORTUGA COMPANHIAZOOTÉCNICAAGRÁRIA. Noticiário Tortuga. 442 ed., a. 51, 3º trim. 2005. Disponível em: <http:// www.canaltortuga.com.br/noticiario/impressa/pdf/442.pdf $>$. Acesso em: 16 nov. 2005.

VENERENDA, N. RDC 210 traz novas exigências para BPF. Revista Controle de Contaminação, São Paulo, ano 7, n. 57. 2004

WOOD MACKENZIE. Animal health industry review and outlook. Disponível em: <http://www.woodmacresearch.com/ cgibin/LifeSci/Animal/animal_init.jsp?cpSessionID=@@@@ 0350365250.1145571575@@@@\&cpEngineID=cccdaddhiee gedfcflgcegjdffjdgig.0>. Acesso em: 20 abr. 2006.

WORLD BANK. World development indicators: economy: tables: growth of output. Disponível em: <http://www. worldbank.org/data/wdi2005/wditext/Section4.htm>. Acesso em: 17 maio 2005.

YIN, R. K. Estudo de caso: planejamento e métodos. Porto Alegre: Bookman, 2 ed., 205p., 2001. 


\section{Sobre os autores}

\section{Felipe Araújo Calarge}

\section{Eduardo Guilherme Satolo}

Universidade Metodista de Piracicaba - UNIMEP

Rod. Iracemápolis - SBO, Km 01, CEP 13450-000, Santa Bárbara d’Oeste, São Paulo, Brasil,

e-mails: fcalarge@unimep.br; egsatolo@unimep.br

\section{Luiz Fernando Satolo}

Universidade de São Paulo - USP,

Av. Dona Jane Conceição, 1385, CEP 13403-030, Piracicaba, São Paulo, Brasil,

e-mail: Ifsatolo @esalq.usp.br

Agradecimentos: Ao CNPq pelo apoio financeiro prestado com a concessão de bolsas de pesquisa; à Faculdade de Engenharia, Arquitetura e Urbanismo da Universidade Metodista de Piracicaba, pelos recursos e infra-estrutura disponibilizados; e às empresas participantes desta pesquisa pelas informações fornecidas. 